\title{
Effects of varying content of soluble dietary fibre from wheat flour and oat milling fractions on gastric emptying in pigs
}

\author{
BY HELLE N. JOHANSEN ${ }^{1,2}$, K. E. BACH KNUDSEN ${ }^{1}$, \\ BRITTMARIE SANDSTRÖM² AND F.SKJØTH ${ }^{3}$ \\ ${ }^{1}$ Danish Institute of Animal Science, Department of Nutrition, \\ Research Centre Foulum, PO Box 39, DK-8830 Tjele, Denmark \\ ${ }^{2}$ Research Department of Human Nutrition, The Royal Veterinary and Agricultural University, \\ Rolighedsvej 25, DK-1870 Frederiksberg C, Copenhagen, Denmark \\ ${ }^{3}$ Danish Institute of Plant and Soil Science, Department of Biometry and Informatics, \\ Research Centre Foulum, PO Box 23, DK-8830 Tjele, Denmark
}

(Received 28 July 1993 - Revised 6 February 1995 - Accepted 5 June 1995)

\begin{abstract}
Four pigs fitted with a gastric cannula were fed on a wheat-flour-based diet (WF) and three oat-based diets, consisting mainly of oat flour $(\mathrm{OF})$, rolled oats (RO) or oat bran (OB), for 1 week each. The stomach contents were collected quantitatively daily at $0.5,1,2,3$ or $5 \mathrm{~h}$ after feeding. The viscosity ( $\mathrm{mPa} . \mathrm{s}$ ) of the liquid fraction of stomach contents $1 \mathrm{~h}$ after feeding was 1.7 with diet WF, 15 with diet $O F, 30$ with diet $R O$ and approximately 400 with diet $O B$. The viscosity and the concentration of $\beta$-glucan in the liquid phase was to some extent determined by the dietary level of $\beta$-glucan in the diet. However, there was a trend towards a lower viscosity after longer exposure to the gastric juices. The correlation between logarithmic values for viscosity and concentration of $\beta$-glucan in the liquid phase of digesta was $r$ 0-45. On centrifugation of digesta there was a higher proportion present in the sediment phase when the pigs were fed on diets with a higher content of soluble dietary fibre (DF), suggesting that the digesta was more coherent. This possibility was supported by the higher water-holding capacity (WHC) of the sediment. Feeding diets with oats containing a higher soluble DF content led to lower recoveries of digesta, PEG 4000 (liquid-phase marker), and the DF components $\beta$-glucan and arabinoxylan in the first hour after feeding. No effect related to the DF content of the diet was seen in the gastric emptying of starch and $\mathrm{Cr}_{2} \mathrm{O}_{3}$ (solid-phase marker). In conclusion, soluble DF from oats increased the viscosity of stomach contents and increased the ability of the dry matter to retain water. Higher levels of soluble DF led to higher recoveries of digesta, the liquid phase and DF itself in the initial stage of gastric emptying, whereas no effect was seen on the gastric emptying of starch.
\end{abstract}

B-Glucan: Oats: Viscosity: Gastric emptying

The effect of various types of dietary fibre (DF) on gastrointestinal function relates highly to their physico-chemical properties and is strongly dependent on the chemical composition and structural integrity of the plant cell wall (Morris, 1992). Insoluble types of DF such as cellulose and wheat bran have shown little or no effect on the rate of passage, digestion and absorption in stomach and small intestine (Stephen \& Cummings, 1980; Low, 1990). In contrast, soluble DF sources have generally been shown to delay absorption of glucose, resulting in attenuated post-prandial peripheral glucose and insulin responses to carbohydrate meals in both man and animals (e.g. Jenkins et al. 1978; Ebihara et al. 1981; Simões Nunes \& Malmlöf, 1992). This effect is thought to be mediated by a reduced rate of gastric emptying and/or a direct effect on the diffusion and absorption of nutrients in the small intestine (Ebihara et al. 1981; Jenkins et al. 1987). In this respect the ability of 
soluble DF to increase gut viscosity is generally considered to play a major role (e.g. Jenkins et al. 1978; Blackburn et al. 1984). However, reports on the effect of soluble DF on gastric emptying are ambiguous. Gastric emptying is slowed and the glycaemic response impaired when soluble DF is added to liquid glucose test meals (Holt et al. 1979; Ebihara et al. 1981; Torsdottir et al. 1991), but results concerning the effects on solid meals are less consistent (Flourie et al. 1985; Rainbird \& Low, 1986a, b; Cherbut et al. 1990). The form in which the DF has been included in the meals, e.g. as isolated or intact cell-wall polysaccharides, and hydration may partly explain differences in the results obtained (Low, 1990). Furthermore, most published results relate to the viscosity of the meal and rarely to the viscosity of the matrix at the site where its physiological function is supposed to take place (Cherbut et al. 1990); this can bias conclusions about the physiological role of viscosity quite significantly for some types of soluble DF (Edwards et al. 1987).

Delayed gastric emptying of semi-synthetic meals containing various levels of fullyhydrated guar gum and different DF sources was confined to the liquid phase of digesta in a study with pigs fitted with a gastric cannula (Rainbird \& Low, 1986 $a, b$ ). These investigators found no effect on the gastric emptying of DM and glucose. This contradicts other reports of delayed gastric emptying of both water and carbohydrates in meals fed to human subjects (Flourie et al. 1985). In contrast to findings of most studies, an accelerated gastric emptying rate was observed when barley was replaced by $50 \mathrm{~g}$ guar gum or pectin $/ \mathrm{kg}$ in gastric-cannulated pigs (Potkins et al. 1991). Reducing the particle size of a barley-based diet accelerated gastric emptying half-time $\left(t_{\frac{1}{2}}\right)$ significantly in one experiment but not in another (Potkins et al. 1991). These findings indicate that the structure and particle size are also important in relation to gastric-emptying rates.

Oat products are naturally rich in soluble DF in the form of mixed-linked $\beta$-glucan. In a previous study with pigs fitted with re-entrant cannulas in the proximal jejunum we were not able to detect differences in the jejunal output of digesta and DM in relation to dietary level of soluble DF up to $3 \mathrm{~h}$ after feeding (Johansen \& Bach Knudsen, 1994). However, continuous collection from re-entrant cannulas in the proximal duodenum indicated more rapid gastric emptying of DM, $\mathrm{N}$ and starch in the first $2 \mathrm{~h}$ after feeding when compared with direct collection of stomach contents from a gastric cannula (Cuber et al. 1980). Thus, we decided to study the effect of wheat-flour- and three oat-based diets with different $\beta$-glucan contents on gastric emptying by collection of digesta at different periods after feeding from pigs fitted with a gastric cannula as described by Low et al. (1985).

\section{EXPERIMENTAL}

Animals and surgery

Four crossbred castrated male pigs of 32.9 (SD 4.7) $\mathrm{kg}$ initial live weight were sedated with $4 \mathrm{mg}$ Sedaperone Vet (Janssenpharma A/S, Birkerød, Denmark) $/ \mathrm{kg}$ live weight given intramuscularly and anaesthetized with $5 \mathrm{mg}$ Hypnodil Vet (Janssenpharma A/S) $/ \mathrm{kg}$ given intravenously. The pigs were then intubated and anaesthetized with halothane (2-bromo2-chloro-1,1,1-trifluorethane; $10 \mathrm{ml} / 1)$ in $\mathrm{O}_{2}(2000 \mathrm{ml} / \mathrm{min})$ using a closed-circuit (bag-inbottle) ventilator (Dameca MCM801; Dameca, Rødovre, Denmark). After a laparotomy had been performed on the right flank the halothane concentration was reduced to $5 \mathrm{ml} / 1$ during surgery. The pigs were fitted with a gastric cannula (i.d. $29 \mathrm{~mm}$ ) in the fundic region, according the procedure described in detail by Low et al. (1985). After a 2 week recovery period, experiments were carried out for four consecutive weeks. All pigs performed well during the experiment and had a normal growth rate (713 (SD 198) g/d). 


\section{Diets and feeding}

The four experimental diets were prepared from commercial sources of wheat flour (WF; Valsemøllen, Esbjerg, Denmark), rolled oats (RO; OTA A/S, Nakskov, Denmark); oat flour (OF) and oat bran (OB; Kungsörnen AB, Järna, Sweden). Ingredients and chemical composition of the diets are given in Table 1. Diets RO and OB were milled to pass through a $2.5 \mathrm{~mm}$ screen. The pigs were fed on the diets for 1 week each in a $4 \times 4$ Latin Square design in three equal meals at $07.00,15.00$ and 22.00 hours. The total daily feed intake was $35 \mathrm{~g} / \mathrm{kg}$ body weight and feed: water ratio was $1: 2 \cdot 5$. PEG 4000 (PEG) was used as a watersoluble marker and $6 \mathrm{~g}$ was dissolved in the water before mixing with the feed at all meals. The diets contained $1 \mathrm{~g} \mathrm{Cr}_{2} \mathrm{O}_{3} / \mathrm{kg}$ as a solid-phase marker.

\section{Collection procedure}

Once every day (Monday-Friday) gastric contents were collected in a randomized order $0 \cdot 5,1,2,3$ or $5 \mathrm{~h}$ after the morning feed as described by Low et al. (1985). Digesta, which flowed freely out of the stomach after insertion of the collection tube, was collected and weighed. This was termed undiluted digesta. The stomach was then rinsed with warm water $\left(38^{\circ}\right)$. Water was poured into the stomach two to three times via the gastric cannula and collected in a bottle by spontaneous outflow from the cannula. Rinsing was completed when the rinses appeared clear and free of particles. The pooled rinses was termed diluted digesta. The total amount of water used for rinsing did not exceed the amount of water ingested by the pig, except when collecting digesta of diet $O B$, where the amount did not exceed twice the amount of water ingested. Undiluted digesta was returned to the stomach after sampling. Collection was usually completed in less than $5 \mathrm{~min}$. In a pre-trial experiment no material was collected from the gastric cannula by rinsing with water. The amount of liquid collected from the cannula during rinsing was equal to or less than the amounts used to rinse the stomach, and the rinses appeared free of solid particles. Subsequently, no pre-feed sample was taken from the stomach and amounts present in the stomach from the previous meal were considered negligible. Most of the DM was collected with the undiluted digesta $(0 \cdot 79-0 \cdot 94)$ for diets WF, OF and RO, but from diet OB less DM was collected $(0.43-0.75)$ before rinsing. Furthermore it was necessary to use more water to obtain quantitative collection of dietary materials with diet $\mathrm{OB}$, and in order to limit the time of collection the stomach was sometimes rinsed before the spontaneous flow was complete. It was assumed that the composition of DM in undiluted digesta was representative of all gastric material.

\section{Analytical procedures}

Centrifugation. Immediately after collection from the stomach a sample of undiluted digesta was distributed between four $50 \mathrm{ml}$ centrifuge tubes and centrifuged at $12000 \mathrm{~g}$ for $20 \mathrm{~min}$ at $4^{\circ}$. After weighing, the supernatant fraction was removed by suction and the centrifuge tubes were turned upside down to drain off residual supernatant fraction for at least $1 \mathrm{~h}$ before re-weighing. The fraction of digesta $(\mathrm{g} / \mathrm{kg})$ present in the sediment was calculated.

Water-holding capacity $(W H C)$. The sediment was dried in the centrifuge tubes in a vacuum oven at $50^{\circ}$ for $16 \mathrm{~h}$ and weighed again to calculate the DM content of the sediment. WHC was calculated as the amount of water retained in the sediment after centrifugation and removed in the drying procedure.

Viscosity. Immediately after centrifugation viscosity of the supernatant fraction was measured in a Brookfield DV-II cone/plate viscometer (Brookfield Engineering Labora- 
Table 1. Composition of experimental diets

\begin{tabular}{|c|c|c|c|c|}
\hline Diet... & WF & OF & RO & $\mathrm{OB}$ \\
\hline \multicolumn{5}{|l|}{ Ingredients $(\mathrm{g} / \mathrm{kg})$} \\
\hline Wheat flour & 793 & - & - & - \\
\hline Oat flour & - & 838 & - & - \\
\hline Rolled oats & - & - & 884 & - \\
\hline Oat bran & - & - & - & 969 \\
\hline Casein & 106 & 111 & 85 & - \\
\hline Soyabean oil & 70 & 20 & - & - \\
\hline Vitamin-mineral mixture* & 30 & 30 & 30 & 30 \\
\hline $\mathrm{Cr}_{2} \mathrm{O}_{3}$ & 1 & 1 & 1 & 1 \\
\hline \multicolumn{5}{|c|}{ Chemical composition (g/kg DM) } \\
\hline Starch & 603 & 606 & 576 & 440 \\
\hline Protein $(\mathrm{N} \times 6.25)$ & 212 & 214 & 203 & 203 \\
\hline HCl-fat & 100 & 87 & 76 & 100 \\
\hline Ash & 37 & 41 & 46 & 59 \\
\hline NSP & 32 & 37 & 78 & 154 \\
\hline S-NSP & 18 & 23 & 47 & 90 \\
\hline I-NSP & 14 & 13 & 31 & 64 \\
\hline$\beta$-glucan & 4 & 16 & 40 & 86 \\
\hline Arabinoxylan & 20 & 9 & 24 & 48 \\
\hline Xylose & 11 & 4 & 12 & 24 \\
\hline Arabinose & 8 & 4 & 10 & 18 \\
\hline Uronic acid & 1 & 2 & 3 & 5 \\
\hline Klason lignin & ND & ND & 7 & 14 \\
\hline Dietary fibre & ND & ND & 84 & 168 \\
\hline Gross energy (MJ/kg DM) & $20 \cdot 36$ & $19 \cdot 80$ & $19 \cdot 66$ & 19.88 \\
\hline $\mathrm{Cr}_{2} \mathrm{O}_{3}$ & 1.06 & $1 \cdot 11$ & $1 \cdot 14$ & $1 \cdot 12$ \\
\hline \multicolumn{5}{|l|}{ Water extracts $\dagger$} \\
\hline$\beta$-glucan $(\mathrm{mg} / \mathrm{ml})$ & 0.5 & $2 \cdot 5$ & $2 \cdot 9$ & 6.0 \\
\hline Viscosity (mPa.s) & $1 \cdot 2$ & 27 & 40 & ND \\
\hline
\end{tabular}

WF, wheat flour; OF, oat flour; RO, rolled oats; OB oat bran; $\mathrm{HCl}$-fat, hydrochloride acid-hydrolysed fat; S-NSP, soluble NSP; I-NSP, insoluble NSP; dietary fibre, NSP + Klason lignin; ND, not determined.

* Provided (mg/kg diet): $\mathrm{Ca}_{2}\left(\mathrm{PO}_{4}\right)_{3}$ 17000, $\mathrm{K}_{2} \mathrm{PO}_{4}$ 5700, $\mathrm{NaCl} 4000, \mathrm{CaCO}_{3} 2500, \mathrm{FeSO}_{4} .7 \mathrm{H}_{2} \mathrm{O} 212, \mathrm{ZnO}$ $85, \mathrm{MnO} 31, \mathrm{CuSO}_{4} .5 \mathrm{H}_{2} \mathrm{O} 68, \mathrm{KI} 0 \cdot 2, \mathrm{Na}_{2} \mathrm{SeO}_{3} .5 \mathrm{H}_{2} \mathrm{O} 0 \cdot 6$, retinyl acetate $1 \cdot 3$, cholecalciferol 0.02 , $\alpha$-tocopherol 43 , menadione $1 \cdot 7$, riboflavin 3.4 , pantothenic acid 8.5 cobalamin 0.02 .

$\dagger$ Diets ( $24 \mathrm{~g} / 100 \mathrm{~g}$ suspension) extracted in water for $1 \mathrm{~h}$ at $38^{\circ}$ and centrifuged at $12000 \mathrm{~g}$ for $20 \mathrm{~min}$ at $4^{\circ}$.

tories Inc., Stoughton, MA, USA) at $38^{\circ}$ and shear rates from $1 \cdot 15$ to $450 / \mathrm{s}$. Absolute viscosity ( $\mathrm{mPa} . \mathrm{s})$ at $45 / \mathrm{s}$ is presented. When measurable viscosity was not in the region of $45 / \mathrm{s}$, data were plotted as $\log$ (shear rate) $v$. $\log$ (absolute viscosity), which gave a straight line from which the line could be extrapolated to $45 / \mathrm{s}$.

Diets were extracted in water ( $24 \mathrm{~g}$ material per $100 \mathrm{~g}$ suspension) in capped $50 \mathrm{ml}$ centrifuge tubes at $38^{\circ}$ for $1 \mathrm{~h}$ with constant stirring and subsequently treated like digesta.

Chemical analyses. $\mathrm{Cr}_{2} \mathrm{O}_{3}$ (Schurch et al. 1950) and PEG (Hyden, 1955) levels were measured using wet undiluted digesta. DM contents of undiluted and diluted digesta were determined by freeze-drying followed by drying at $105^{\circ}$ for $24 \mathrm{~h}$. Protein $(\mathrm{N} \times 6.25)$ was determined by the Kjeldahl method using a Kjell-Foss 16200 autoanalyser (Foss Electric A/S, Hillerød, Denmark) and energy was measured in a LECO AC 300 automated calorimeter system 789-500 (LECO, St Joseph, MI, USA). Ash was analysed according to the American Association of Official Analytical Chemists (1975) and fat was extracted with diethyl ether after acid-hydrolysis (Stoldt, 1952).

Starch was analysed by the enzymic method described by Bach Knudsen et al. (1993). 
NSP and Klason lignin was determined as described in detail by Bach Knudsen et al. (1993). Arabinoxylan was calculated as the sum of the anhydro-sugars of arabinose, xylose and uronic acids. $\beta$-Glucan concentrations of diets, freeze-dried undiluted digesta and of the digesta supernatant fraction were determined by the enzymic method of McCleary \& Glennie-Holmes (1985; MegaZyme Pty Ltd, Warriewood, Australia).

All analyses on diets and digesta were performed in duplicate.

\section{Calculation and statistical analyses}

The proportion of dietary components and marker retained in the stomach at time $t_{i}$ after feeding $\left(R_{i}\right)$ was calculated as:

$$
R_{i}=\frac{M_{i}}{M_{o}}
$$

where $M_{i}$ is the amount of component collected at time $t_{i}$ after feeding and $M_{o}$ is the amount in the meal.

The following linear normal model was used for analysis of the data:

$$
\mathrm{Y}_{i j k l}=\mu+\alpha_{i}+\beta_{j}+\gamma_{k}+\alpha \beta \gamma_{i j k}+\delta_{l}+\alpha \delta_{i l}+\beta \delta_{j l}+\gamma \delta_{k l}+\epsilon_{i j k l},
$$

where $\mu$ is the overall mean, $\alpha_{i}$ is the effect of diet, $i=1, \ldots 4, \beta_{j}$ is the effect of week, $j=1, \ldots 4, \gamma_{k}$ is the effect of animal, $k=1, \ldots 4, \delta_{l}$ is the effect of time, $l=1, \ldots 5$. The variance components $\alpha \beta \gamma_{i j k}$ represents independent normally distributed between-unit (whole-plot) variation $\left(0, \sigma_{\mathrm{M}}^{2}\right)$ and $\epsilon_{i j k l}$ the measurement error (sub-plot error; $0, \sigma^{2}{ }_{1}$ ).

The underlying assumption of sphericity was tested by means of Mauchy's criterion in a multivariate ANOVA (Statistical Analysis Systems Institute, 1986) and was found to be appropriate for all variables. The model is a split-plot design with a Latin Square design as whole plot. Whole-plot factors were tested $v$. the whole-plot error and sub-plot factors $v$. the residual. Assumptions of homogenity of variance and normality were checked by residual analysis. In three cases (viscosity, $\beta$-glucan concentration and proportion of $\beta$-glucan in solution) it was found necessary to stabilize the variance by using logarithmic transformation (natural logarithm).

The correlation between viscosity and concentration of $\beta$-glucan in the liquid phase, both subjected to logarithmic transformation, was investigated by means of a two-dimensional multivariate ANOVA. The stated significant correlation is based on the assumption of the following model:

$$
Y_{i j k l}=\mu+\alpha_{i}+\beta_{j}+\gamma_{k}+\alpha \beta \gamma_{i j k}+\delta_{l}+\alpha \delta_{i l}+\epsilon_{i j k l},
$$

where the omitted interactions from equation 2 were not significant.

A model for gastric emptying $t_{\frac{1}{2}}$ calculated from a mono-exponential function from:

$$
R_{(t)}=a \times b^{t},
$$

as $\log 2 / \log b$, where $-\log b$, the slope of the regression of $\log R_{(t)} v$. time, has been used in previous studies (e.g. Rainbird \& Low, 1986 $a, b$; Flourie $e t$ al. 1985). The model assumes that the logarithmic transformation of $R$ is linear in $t$. It was found that this assumption was seldom applicable to these data. Instead the data were analysed as described previously.

\section{RESULTS}

Viscosity and concentration of $\beta$-glucan in the liquid phase of digesta

The viscosity of the liquid phase of the gastric contents was significantly higher after intake of the oat-based diets compared with diet WF which at all periods had a viscosity of 


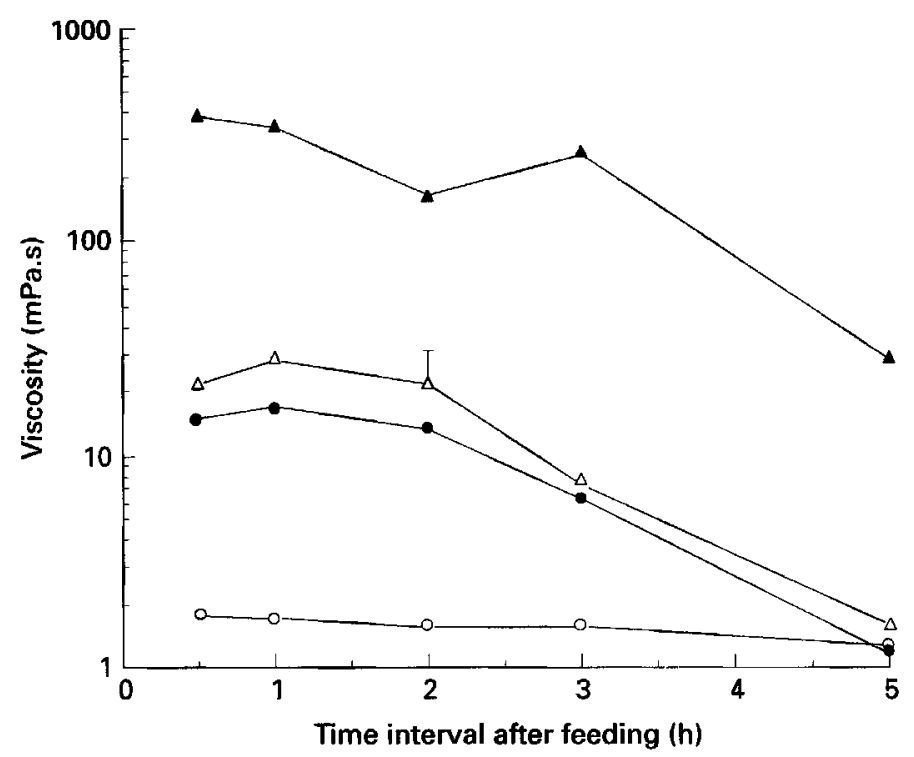

Fig. 1. Viscosity ( $\mathrm{mPa} . \mathrm{s}$ ) in the liquid phase of gastric contents of pigs $0 \cdot 5,1,2,3$ and $5 \mathrm{~h}$ after feeding diets based on wheat flour $(\mathbf{O})$, oat flour $(\boldsymbol{O})$, rolled oats $(\triangle)$ and oat bran $(\mathbf{A})$. For details of experimental diets and procedures, see Table 1 and pp. 340-343. Points are mean values with their standard errors, represented by vertical bars, for four pigs.

approximately $1.6 \mathrm{mPa}$.s (Fig. 1). The viscosity was ten times higher with diet $\mathrm{OF}$ compared with diet WF up to $2 \mathrm{~h}$ after feeding, but diets OF and RO did not induce significantly different viscosities up to $2 \mathrm{~h}$ after feeding. Diet $\mathrm{OB}$ resulted in a viscosity for the gastric contents which was almost fifteen times higher than that for diet RO at $1-2 \mathrm{~h}$ after feeding. For all oat-based diets viscosity of digesta was increased slightly from 0.5 to $1 \mathrm{~h}$ after feeding, but was significantly reduced at $5 \mathrm{~h}$ after feeding.

The concentration of $\beta$-glucan in the liquid phase was almost constant for each diet except for a significant reduction $5 \mathrm{~h}$ after feeding (Table 2). The concentration in the liquid digesta was not significantly different when diets OF and RO were fed, even though the concentration of $\beta$-glucan in the latter diet was more than 2.5 times higher. This was due to a significantly higher solubility of $\beta$-glucan in diet OF than diet RO at all collection times except at $3 \mathrm{~h}$ after feeding. In contrast the $\beta$-glucan concentration of the liquid phase of the digesta was twice as high with diet $\mathrm{OB}$ as that with RO, the degree of solubilization was almost identical for the two diets. $\beta$-Glucan from diet WF had the highest solubility, which was significantly different from that of the oat-based diets at all collection times except at $3 \mathrm{~h}$ after feeding. However, it resulted in a significantly lower concentration of $\beta$-glucan in the liquid phase of digesta due to the low content in the diet.

The two-dimensional multivariate ANOVA showed a partial correlation coefficient for viscosity $v, \beta$-glucan concentration of $r 0.4502, P=0.0013$. Viscosity $v$, the concentration of $\beta$-glucan in the liquid phase is shown in Fig. 2.

Extraction of diets WF, OF and RO in water for $1 \mathrm{~h}$ with constant stirring resulted in concentrations of $\beta$-glucan in the supernatant fraction that were almost identical to the concentrations in digesta $(0.5,2.5$ and $2.9 \mathrm{mg} / \mathrm{ml}$ respectively) (Table 1$)$. The concentration was slightly higher $(6.0 \mathrm{mg} / \mathrm{ml})$ when extracting diet $\mathrm{OB}$ in water. 
SOLUBLE DIETARY FIBRE AND GASTRIC EMPTYING

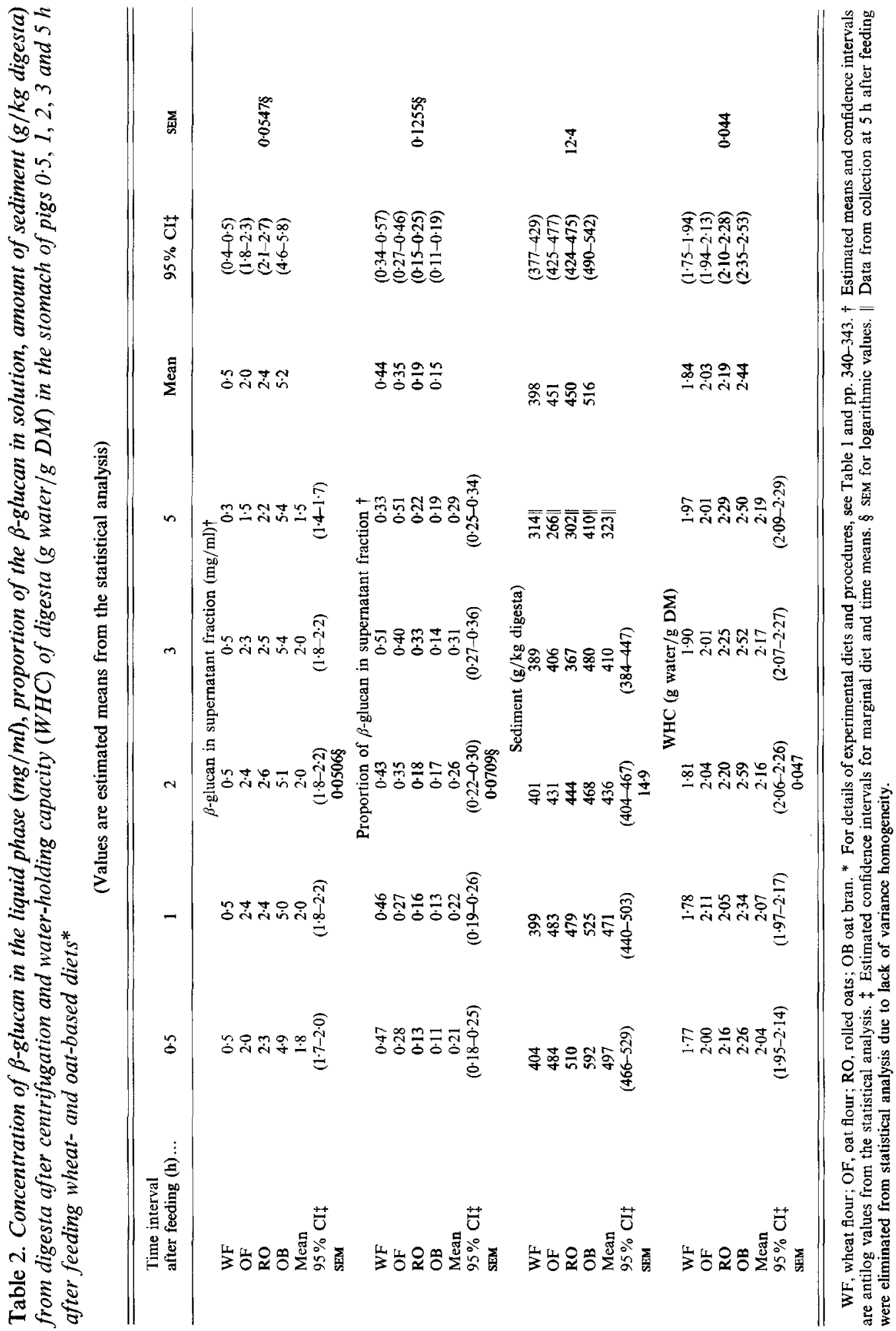




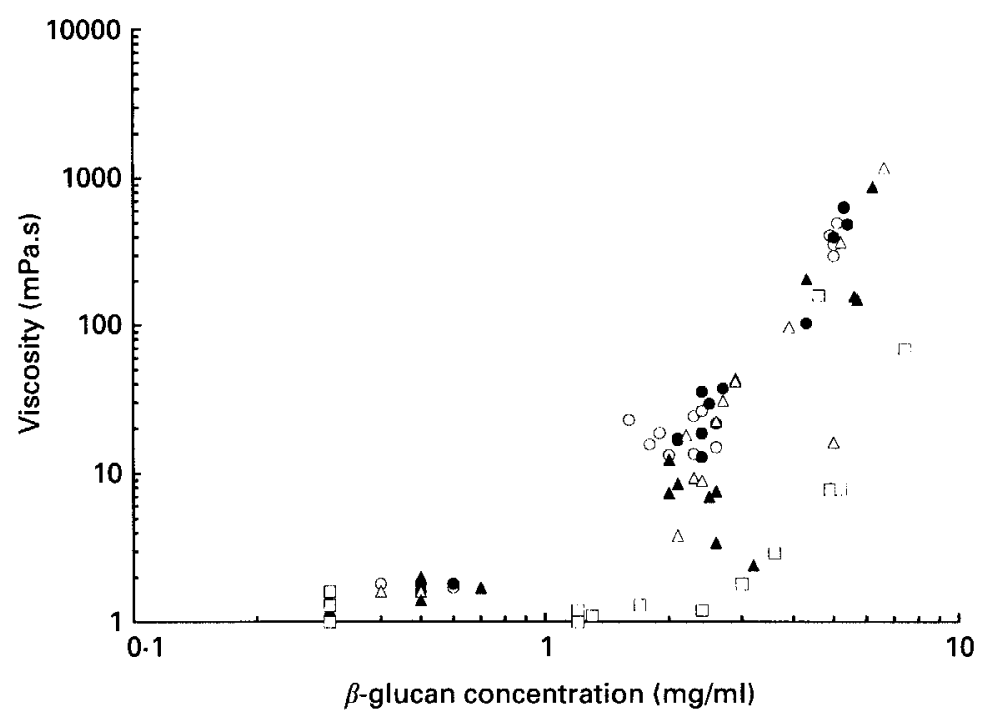

Fig. 2. Viscosity (mPa.s) v. concentration of $\beta$-glucan $(\mathrm{mg} / \mathrm{ml})$ in the liquid phase of the stomach contents of pigs $0 \cdot 5,(\bigcirc), 1(\mathcal{O}), 2(\triangle) 3(\Delta)$ and $5(\square) \mathrm{h}$ after feeding wheat- and oat-based diets. For details of experimental diets and procedures, see Table 1 and pp. $340-343$.

\section{Sediment fraction of digesta and water-holding capacity}

The relative amount of digesta present in the sediment fraction after centrifugation increased in response to higher dietary levels of $\beta$-glucan; with diet OB marginal means were significantly higher than those for the other diets. Values for diet WF were significantly lower than those for the oat-based diets (Table 2). There was a decrease with time so that the proportion of digesta present in sediment fraction was significantly lower $3 \mathrm{~h}$ after feeding than at 0.5 and $1 \mathrm{~h}$ after feeding. WHC of digesta increased significantly with increasing $\beta$-glucan content in the diet, so that all diets were significantly different from each other with regard to marginal diet means (Table 2). There was an increase in WHC of digesta with residence time in the stomach, but only at 0.5 and $5 \mathrm{~h}$ were there significant differences in marginal time means.

\section{Gastric emptying}

In the statistical analysis of the recovery of components with time as a split-plot there was no significant interaction between time and diet for digesta $(P=0 \cdot 1809), \mathrm{DM}(P=0 \cdot 2195)$, $\mathrm{Cr}_{2} \mathrm{O}_{3}(P=0.5313)$, starch $(P=0.2179)$, NSP $(P=0.4225), \beta$-glucan $(P=0.3838)$ and arabinoxylan $(P=0.3804)$, whereas a significant interaction was found for $P E G$ $(P=0.0001)$. This suggests that for most components measured the diets did not have different effects on the gastric emptying pattern in the time interval studied, although different levels might occur. However, in a reduced statistical model where the nonsignificant interaction of diet and time was eliminated, no significant effect of diet was found for the recovery of digesta $(P=0.0609), \mathrm{DM}(P=0.1395), \mathrm{Cr}_{2} \mathrm{O}_{3}(P=0.5079)$ and starch $(P=0.6161)$. There was a significant overall effect of diet for NSP $(P=0.0019)$, $\beta$-glucan $(P=0.0005)$ and arabinoxylan $(P=0.0031)$. In the case of total NSP diets WF and OF were significantly different from diets RO and OB. Diet WF deviated significantly from all oat-based diets in the level of recovery of $\beta$-glucan, diet OF was significantly different from diet $\mathrm{OB}$, whereas diet RO did not deviate significantly from either diet $\mathrm{OF}$ 
Table 3. Recoveries of digesta, DM, solid-phase (chromic oxide) and liquid-phase (PEG) markers, and dietary components (starch, $\beta$-glucan, NSP and arabinoxylan) from the stomach 0.5-5 h after feeding wheat- and oat-based diets*

(Values are estimated means from the statistical analysis)

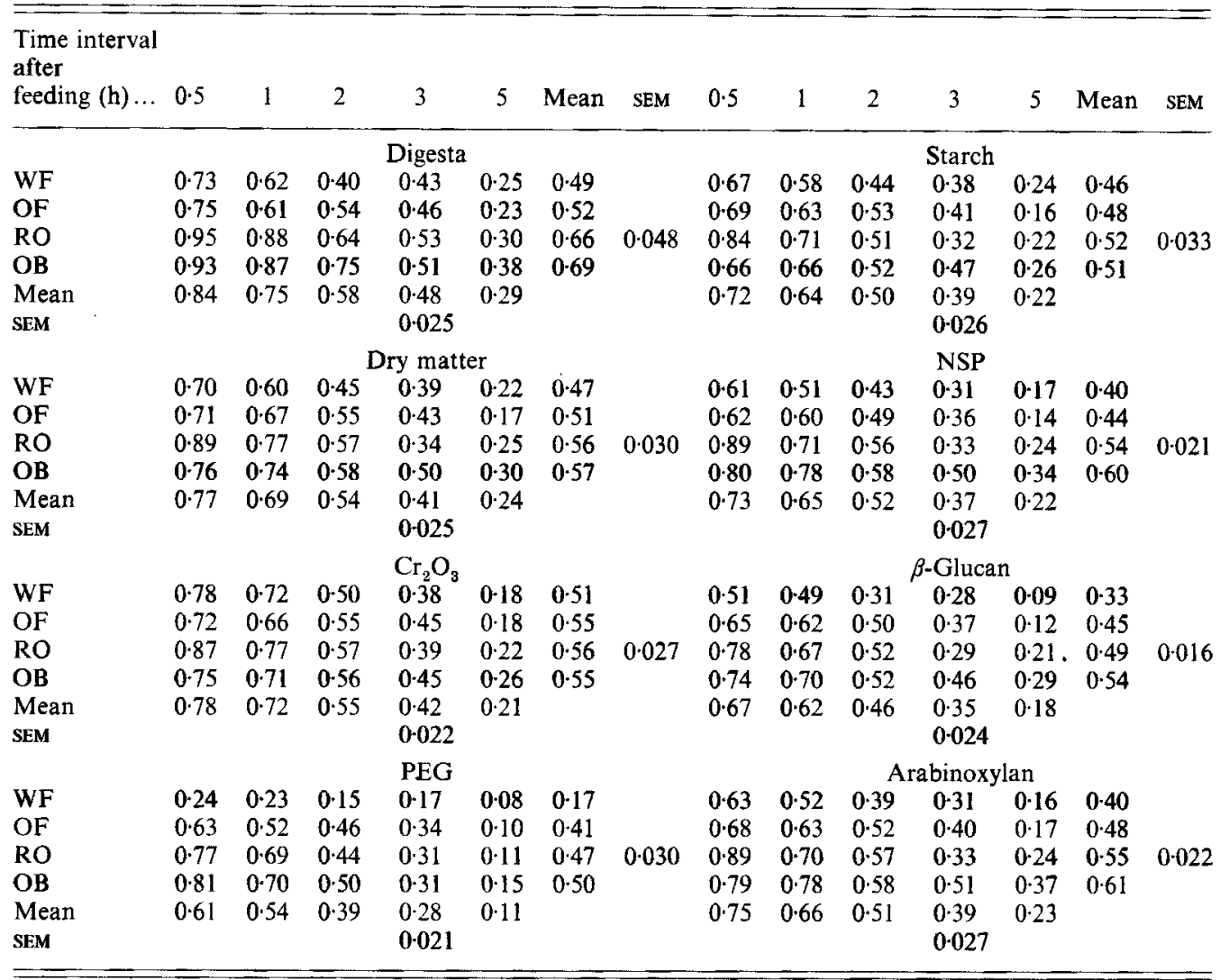

WF, wheat flour; OF, oat flour; RO, rolled oats; OB, oat bran.

* For details of experimental diets and procedures, see Table 1 and pp. 340-343.

or diet OB. Diets WF and OF were significantly different from diet $O B$ in the emptying of arabinoxylan, whereas diet RO did not deviate significantly from diets OF and OB.

For all components there was a significant overall effect of time, with the recovery at each collection time being significantly different from each other.

Recovery of markers and dietary components at each separate time-point

Digesta. The relative amounts of digesta retained at 0.5 and $1 \mathrm{~h}$ after feeding were significantly higher for diets RO and $\mathrm{OB}$ than those for diets WF and OF (Table 3). At $2 \mathrm{~h}$ after feeding significantly less digesta was recovered with diet WF compared with the other diets and significantly less was recovered with diet $\mathrm{OF}$ compared with diet $\mathrm{OB}$. After $5 \mathrm{~h}$, diets $O F$ and $O B$ differed significantly from each other in the retained amount of digesta.

$D M$. Diet RO resulted in a significantly higher recovery than diets WF and OF at $0.5 \mathrm{~h}$ after feeding, whereas both diets $\mathrm{RO}$ and $\mathrm{OB}$ gave a higher DM recovery than diet WF at $1 \mathrm{~h}$ after feeding. On the other hand the recovery from diet $\mathrm{RO}$ was significantly lower than that from diet $\mathrm{OB}$ at $3 \mathrm{~h}$ after feeding. 
Chromic oxide. The amount of $\mathrm{Cr}_{2} \mathrm{O}_{3}$ retained in the stomach was not significantly affected by the diet except for a significantly higher recovery from diet RO compared with diets $O F$ and $O B$ at $0.5 \mathrm{~h}$ after feeding.

$P E G$. The gastric emptying of PEG appeared to be much faster for diet WF compared with the oat-based diets. The recovery of PEG was significantly lower up to $3 \mathrm{~h}$ after feeding and that for diet $O F$ differed from values for diets $R O$ and $O B$ at 0.5 and $1 \mathrm{~h}$ after feeding.

Starch. In general there were no significant differences in the amounts of starch collected from the different diets except for a significantly higher recovery from diet RO than from all other diets at $0.5 \mathrm{~h}$ after feeding.

NSP. The proportion of NSP retained in the stomach at 0.5 and $1 \mathrm{~h}$ after feeding was significantly higher for diets $\mathrm{RO}$ and $\mathrm{OB}$ than that collected from diets WF and $\mathrm{OF}$, but no significant differences were found between diets at later stages.

$\beta$-Glucan. Significantly less $\beta$-glucan was retained in the stomach with diet WF compared with diets $\mathrm{RO}$ and $\mathrm{OB}$ at 0.5 and $1 \mathrm{~h}$ after feeding and was less than that for all oat-based diets at $2 \mathrm{~h}$ after feeding. At $5 \mathrm{~h}$ after feeding both diets $\mathrm{RO}$ and $\mathrm{OB}$ resulted in a significantly higher recovery of $\beta$-glucan than did diets WF and OF.

Arabinoxylan. Diets WF and OF had a significantly lower recovery than diets RO and $\mathrm{OB}$ at $0.5 \mathrm{~h}$ after feeding, whereas only diets WF and OB differed significantly after $1 \mathrm{~h}$. At $2 \mathrm{~h}$ after feeding, none of the diets was significantly different, but diet $\mathrm{OB}$ had a significantly higher recovery than diets WF and RO at $3 \mathrm{~h}$ after feeding and diets WF and OF at $5 \mathrm{~h}$ after feeding.

\section{DISCUSSION}

The patterns of gastric emptying of the measured components in the present study were not described adequately by a power exponential curve, in contrast to many previous studies (e.g. Rainbird \& Low, 1986a, b; Flourie et al. 1985). Consequently, data describing gastric emptying are only expressed as proportions of the respective intakes remaining in the stomach at different times after feeding. The initial gastric emptying $(0.5$ and $1 \mathrm{~h}$ after feeding) was influenced by the diet in an order that appeared to be related to the DF content in the case of digesta, the DF components, the liquid-phase marker and in part by DM. However, the recovery of PEG obtained from pigs fed on diet WF in the present study was suspiciously low at $0 \cdot 5-3 \mathrm{~h}$ after feeding, which suggests that there might be problems in the analysis of PEG with some diets. The initial lower recovery of $\beta$-glucan, which is partly soluble, is on the other hand also an indication of a more rapid flow of liquid out of the stomach of pigs fed on diets WF and OF compared with diets RO and OB.

Rainbird \& Low $(1986 a, b)$ found that soluble DF delayed gastric emptying of digesta but had no effect on the emptying of DM and glucose in gastric-cannulated pigs fed on semi-purified high-fat diets with various soluble DF sources and levels of guar gum. They concluded that the effect of soluble DF on gastric emptying was confined to the liquid phase. In contrast, Flourie et al. (1985) found that 10-15 g pectin added to a semi-solid meal increased $t_{\frac{1}{2}}$ of both water and carbohydrates in the meal by approximately $150 \%$. In the present study the recovery of starch and the solid-phase marker was not influenced by the diet in a manner that could be explained as an effect of DF, supporting the observations made by Rainbird \& Low $(1986 a, b)$. However, the prolonged gastric emptying of the DF components when the pigs were fed on the two diets with the highest level of DF suggests a slower gastric emptying of NSP itself. This is in line with a selective retention of wheat bran observed by Rainbird \& Low (1986b). Although oat mill fractions are considered rich sources of soluble DF, the present study shows that a rather small proportion of $\beta$-glucan is actually solubilized in the stomach. The $\beta$-glucan in oat bran is concentrated in thick subaleurone cell walls that are structurally more sturdy than the inner endosperm (Yiu et al. 
1987). The cell walls will in part retain their structural integrity and their $\beta$-glucan content in both the stomach and small intestine (Johansen, 1993). Thus, the less-soluble cell walls of the aleurone layer will probably have an emptying behaviour like that of particulate material, which is known to be emptied more slowly than liquids (Meyer et al. 1986; Collins et al. 1991).

The higher recovery of digesta up to $2 \mathrm{~h}$ after feeding, equivalent to a slowed emptying of the liquid phase, might reflect differences in the stimulatory effect on gastric secretion (Low, 1989). The effect of DF on gastric secretion has not been extensively studied, but the volume of secretion has been reported to increase by some authors (Zebrowska et al. 1983; Low, 1990) and not by others (Flourie, 1992).

The study revealed marked changes in rheological behaviour of the stomach contents. Higher levels of $\beta$-glucan derived from intact cell walls significantly elevated the viscosity of the gastric contents, which in the case of diet $\mathrm{OB}$ lasted for at least $5 \mathrm{~h}$. Furthermore, when diets with higher amounts of soluble DF were fed, the amount of liquid that could be obtained on centrifugation of the gastric contents was reduced. WHC of the digesta also increased with higher amounts of soluble DF in the diet. The viscosity-elevating properties of soluble DF are generally accepted as being responsible for delayed gastric emptying, although in vitro viscosity does not necessarily reflect viscosity in vivo (Edwards et al. 1987; Cherbut et al. 1990; Johansen, 1993). Furthermore, the properties of DF isolates differ from those of NSP in natural plant food material (Wood et al. 1990). The large proportion of intact and only partly dispersed cell wall structures will not contribute to the viscosity of the liquid phase of digesta (Wood et al. 1990) but might influence the bulkiness and rheological behaviour of digesta by increased ability to take up water. This was demonstrated in the present study by the larger proportion of sediment after centrifugation and increased WHC with higher dietary levels of $\beta$-glucan. Hence, the rate of dispersion and solubilization of cell walls, along with the degree of depolymerization, are important factors to be considered in the discussion of the potential physiological effect of soluble DF from natural plant food sources in pig and man (Edwards et al. 1987; Wood et al. 1990; Johansen, 1993; Johansen et al. 1993). The lower viscosity of digesta collected 2-5 h after feeding pigs on diets $\mathrm{RO}$ and $\mathrm{OB}$, despite a relatively high concentration of $\beta$-glucan in the liquid phase, indicates that some depolymerization of the $\beta$-glucan took place, as previously shown in jejunal contents from pigs fed on similar diets (Johansen, 1993; Johansen et al. 1993). The concentration of polymer and polymer chain length are the major determinants of viscosity of pure solutions of soluble fibre. Thus, the relatively poor correlation between the concentration of $\beta$-glucan and viscosity in the liquid phase of the stomach of the pigs may be explained partly by microbial depolymerization of the $\beta$-glucan.

Confounding variables other than the content of soluble DF ( $\beta$-glucan), such as differences in physical structure and particle size of the raw materials used, may have had an influence on the results obtained. Diets $\mathrm{RO}$ and $\mathrm{OB}$ were milled to pass a $2.5 \mathrm{~mm}$ screen to minimize differences in particle size between diets, but a higher content of aleurone tissue in these fractions could have influenced the susceptibility to milling, resulting in an apparently higher content of more coarse particles (not measured). The particle size and physical form of the diet are known to influence gastric emptying, with more fine particles being emptied faster from the stomach, and to have a different stimulatory effect on gastric secretion (Meyer et al. 1986; Low, 1989; Potkins et al. 1991). Consequently, with complex meals the effect of NSP on gastric emptying can be difficult to separate from effects of other dietary constituents and food structure (Low, 1990; Torsdottir et al. 1991; Flourie, 1992).

The present study did not provide clear evidence for a delay in gastric emptying when feeding higher levels of soluble DF. However, when discussing gastric emptying as a possible explanation for the beneficial effects of oat products in glycaemic control one must consider the early stage after a meal ( $0-1 \mathrm{~h}$ after feeding) as the most important, since 
usually peak blood glucose responses are obtained within this period. Although no significant effects of DF content on the recovery of starch were seen in this period, there was a general trend towards a higher recovery of the other dietary components when feeding diets with a higher content of soluble DF. Furthermore, since recoveries of starch were identical in the present study, different amounts of starch would be delivered to the small intestine due to differences in the starch content of the diets. Based on the marginal recovery of 0.64 at $1 \mathrm{~h}$ after feeding, $109 \mathrm{~g}$ starch would be emptied from the stomach with diet WF compared with $75 \mathrm{~g}$ starch with diet OB if $500 \mathrm{~g} \mathrm{DM}$ was given at the preceding meal. It is likely that this would lead to differences in blood glucose response. Of course one should provide the same level of available carbohydrate in a study of glycaemic response to a meal, which is very difficult to obtain unless semi-purified diets are used.

\section{Conclusion}

The present findings have demonstrated that feeding oat mill fractions with varying contents of soluble DF in the form of $\beta$-glucan greatly affects the viscosity and rheological behaviour of the stomach content. Feeding diets with higher contents of soluble DF in the form of $\beta$-glucan resulted in a general trend towards slower emptying of the stomach in the first hour after a meal, except for the emptying of starch and $\mathrm{Cr}_{2} \mathrm{O}_{3}$. We conclude that the effect of soluble DF present in intact cell wall structures is much more complex than that with isolated DF sources.

This work was supported by the Danish Agricultural and Veterinary Research Council and the Danish Research Academy. The authors are indebted to Dr Teresa Zebrowska and Dr Graham Low for excellent technical advice in setting up the cannulation and collection technique and to Dr Henry Jørgensen for carrying out surgery. They would like to thank Karl Henrik Jakobsen and Peter Sørensen for careful handling of the pigs and Hanne Lund Jensen, Lene Rasmussen and Helle Clemmensen for skilful technical assistance. Finally, the authors wish to thank Dr Bjørn O. Eggum for his encouragement and advice throughout the study.

\section{REFERENCES}

Association of Official Analytical Chemists (1975). Official Methods of Analysis, 11th ed., Washington, DC: Association of Official Analytical Chemists.

Bach Knudsen, K. E., Jensen, B. B. \& Hansen, I. (1993). Digestion of polysaccharides and other major components in the small and large intestine of pigs fed on diets consisting of oat fractions rich in $\beta$-D glucan. British Journal of Nutrition 70, 537-556.

Blackburn, N. A., Redfern, J. S., Jarjis, H., Holgate, A. M., Hanning, I., Scarpello, J. H. B., Johnson, I. T. \& Read, N. W. (1984). The mechanism of action of guar gum in improving glucose tolerance in man. Clinical Nutrition 66, 329-336.

Cherbut, C., Albina, E., Champ, M., Doublier, J. L. \& Lecannu, G. (1990). Action of guar gums on the viscosity of digestive contents and on the gastrointestinal motor function in pigs. Digestion 46, 205-213.

Collins, P. J., Houhton, L. A., Read, N. W., Horowitz, M., Chatterton, B. E., Heddle, R. \& Dent, J. (1991). Role of the proximal and distal stomach in mixed solid and liquid meal emptying. Gut 32, 615-619.

Cuber, J. C., Laplace, J. P. \& Villiers, P. A. (1980). Fistulation de l'estomac et contenus gastriques résiduels après ingestion d'un régime semi-purifié à base d'amidon de maïs chez le porc (Gastric fistulation and residual gastric contents after ingestion of a semi-purified diet based on maize starch in the pig). Reproduction, Nutrition, Développement 20, 1161-1172.

Ebihara, K., Masuhara, R. \& Kiriyama, S. (1981). Major determinants of plasma glucose-flattening activity of a water-soluble dietary fiber: effects of konjac mannan on gastric emptying and intraluminal glucose-diffusion. Nutrition Reports International 23, 1145-1156.

Edwards, C. A., Blackburn, N. A., Craigen, L. D., Davison, P., Tomlin, J., Sugden, K., Johnson, I. T. \& Read, N. W. (1987). Viscosity of food gums determined in vitro related to their hypoglycemic actions. American Journal of Clinical Nutrition 46, 72-77.

Flourie, B. (1992). The influence of dietary fiber on carbohydrate digestion and absorption. In Dietary Fibre: $A$ Component of Food: Nutritional Function in Health and Disease, pp. 181-196 [T. F. Schweizer and C. A. Edwards, editors]. London: Springer-Verlag, ILSI Human Nutrition Reviews. 
Flourie, B., Vidon, N., Chayvialle, J. A., Palma, R., Franchisseur, C. \& Bernier, J. J. (1985). Effect of increased amounts of pectin on a solid-liquid meal digestion in healthy man. American Journal of Clinical Nutrition $\mathbf{4 2}$, $495-503$.

Holt, S., Heading, R. C., Carter, D. C., Prescott, L. F. \& Tothill, P. (1979). Effect of gel fibre on gastric emptying and absorption of glucose and paracetamol. Lancet $\mathbf{i}, 636-639$.

Hyden, S. (1955). A turbidimetric method for the determination of higher polyethylene glucols in biological material. Kungliga Lantbrukshögskolans Annaler 22, $139-145$.

Jenkins, D. J. A., Jenkins, A. L., Wolever, T. M. S., Collier, G. R., Rao, A. V. \& Thompson, L. U. (1987). Starchy foods and fiber: reduced rate of digestion and improved carbohydrate metabolism. Scandinavian Journal of Gastroenterology 22, 132-141.

Jenkins, D. J. A., Wolever, T. M. S., Leeds, A. R., Gassull, M. A., Haisman, P., Dilawari, J., Goff, D. V., Metz, G. L. \& Alberti, K. G. M. (1978). Dietary fibres, fibre analogues, and glucose tolerance: importance of viscosity. British Medical Journal 1, 1392-1394.

Johansen, H. N. (1993). Dietary fibre from oats: Physico-chemical properties and physiological function in the stomach and small intestine of pigs. PhD Thesis, The Royal Veterinary and Agricultural University, Copenhagen.

Johansen, H. N. \& Bach Knudsen, K. E. (1994). Effects of wheat flour and oat mill fractions on jejunal flow, starch degradation and absorption of glucose over an isolated loop of jejunum in pigs. British Journal of Nutrition 72, 299-313.

Johansen, H. N., Wood, P. J. \& Bach Knudsen, K. E. (1993). Molecular weight changes in the $(1 \rightarrow 3)(1 \rightarrow 4)$ $\beta$-D-glucan of oats incurred by the digestive processes in the upper gastrointestinal tract of pigs. Journal of Agricultural and Food Chemistry 41, 2347-2352.

Low, A. G. (1989). Secretory response of the pig gut to non-starch polysaccharides. Animal Feed Science and Technology 23, 55-65.

Low, A. G. (1990). Nutritional regulation of gastric secretion, digestion and emptying. Nutrition Research Reviews 3, $229-252$

Low, A. G., Pittman, R. J. \& Elliot, R. J. (1985). Gastric emptying of barley-soya-bean diets in the pig: effects of feeding level, supplementary maize oil, sucrose or cellulose, and water intake. British Journal of Nutrition 54 , $437-447$

McCleary, B. V. \& Glennie-Holmes, M. (1985). Enzymatic quantification of $(1 \rightarrow 3),(1 \rightarrow 4)$-D-glucan in barley and mait. Journal of the Institute of Brewing 91, 285-295.

Meyer, J. H., Gu, Y. G., Reedy, T., Freesman, J. \& Amidon, G. (1986). Effects of viscosity and fluid outflow on postcibal gastric emptying of solids. American Journal of Physiology 250, G161-G164.

Morris, E. R. (1992). Physico-chemical properties of food polysaccharides. In Dietary Fibre: A Component of Food: Nutritional Function in Health and Disease, pp. 41-55 [T. F. Schweizer and C. A. Edwards, editors] London: Springer-Verlag, ILSI Human Nutrition Reviews.

Potkins, Z. V., Lawrence, T. L. J. \& Thomlinson, J. R. (1991). Effects of structural and non-structural polysaccharides in the diet of the growing pig on gastric emptying rate and rate of passage of digesta to the terminal ileum and through the total gastrointestinal tract. British Journal of Nutrition 65, 391-413.

Rainbird, A. L. \& Low, A. G. (1986a). Effect of guar gum on gastric emptying in growing pigs. British Journal of Nutrition 55, 87-98.

Rainbird, A. L. \& Low, A. G. (1986 b). Effect of various types of dietary fibre on gastric emptying in growing pigs. British Journal of Nutrition 55, 111-121.

Simões Nunes, C. \& Malmlöf, K. (1992). Effects of guar gum and cellulose on glucose absorption, hormonal release and hepatic metabolism in the pig. British Journal of Nutrition 68, 693-700.

Statistical Analysis Systems Institute (1986). SAS System for Linear Models. Cary, North Carolina: SAS Institute Inc.

Schurch, A. F., Lloyd, L. E. \& Crampton, E. W. (1950). The use of chromic oxide as an index for determining the digestibility of a diet. Journal of Nutrition $\mathbf{5 0}, 629-636$.

Stephen, A. M. \& Cummings, J. H. (1980). Mechanism of action of dietary fibre in the human colon. Nature 284, 283-284.

Stoldt, W. (1952). Vorschlag zur Vereinheitlichung der Fettbestimmung in Lebensmitteln (Suggestions for the standardization of the determination of fat in foodstuffs). Fette, Seifen, Anstrichmittel 54, 206-207.

Torsdottir, I., Alpsten, M., Holm, G., Sandberg, A. S. \& Tolli, J. (1991). A small dose of soluble alginate-fiber affects post-prandial glycemia and gastric emptying in humans with diabetes. Journal of Nutrition 121, 795-799.

Wood, P. J., Braaten, J. T., Scott, F. W., Riedel, D. \& Poste, L. M. (1990). Comparisons of viscous properties of oat and guar gum and the effects of these and oat bran on glycemic index. Journal of Agricultural and Food Chemistry 38, 753-757.

Yiu, S. H., Wood, P. J. \& Weisz, J. (1987). Effects of cooking on starch and $\beta$-glucan of rolled oats. Journal of Cereal Chemistry 64, 373-379.

Zebrowska, T., Low, A. G. \& Zebrowska, H. (1983). Studies on gastric digestion of protein and carbohydrate, gastric secretion and exocrine pancreatic secretion in the growing pig. British Journal of Nutrition 49, 401-410. 